\title{
THE IMPACT OF MEMBERS OF THE SOCIETY OF UNIVERSITY SURGEONS ON THE SCHOLARSHIP OF AMERICAN SURGERY
}

Nakul P. Valsangkar, MD, Joshua K. Kays, MD, David V. Feliciano, MD, Paul J. Martin, Jordan

S. Parett, Mugdha M. Joshi, MD, Teresa A. Zimmers, PhD, Leonidas G. Koniaris, MD, MBA, FACS

\section{Department of Surgery, Indiana University School of Medicine}

Corresponding Author:

Leonidas G. Koniaris, MD

This is the author's manuscript of the article published in final edited form as:

Valsangkar, N. P., Kays, J. K., Feliciano, D. V., Martin, P. J., Parett, J. S., Joshi, M. M., ... \& Koniaris, L. G. (2016). The impact of members of the Society of University Surgeons on the scholarship of American surgery. Surgery, 160(1), 47-53. http://dx.doi.org/10.1016/j.surg.2016.03.016 


\section{$\underline{\text { Abstract }}$}

Objective: A core objective of the Society of University Surgeons (SUS) is research focused: to "advance the art and science of surgery through original investigation." This study sought to determine the current impact of the SUS on academic surgical productivity.

Methods: Individual faculty data for numbers of publications, citations, and National Institute of Health (NIH) funding history were collected for 4,015 surgical faculty at the top 55-NIH funded departments of surgery using SCOPUS and NIH RePORTer. SUS membership was determined from membership registry data.

Results: Overall, 502 surgical faculty $(12.5 \%)$ were SUS members with $92.7 \%$ holding positions of associate or full professor (versus $59 \%$ of non-members). Median publications (P) and citations (C) among SUS members were P:112, C:2460 versus P:29, C:467 $(p<0.001)$. Academic productivity was considerably higher by rank for SUS-members: associate professor (P:61 vs. 36, C:1199 vs. 591, p < 0.001) and full professors (P:141 vs. 81, C:3537 vs. 1856, p < $0.001)$. Among full professors, SUS members had much higher rates of NIH funding $(52.6 \%$ vs. $26 \%, \mathrm{p}<0.05)$ and specifically for R01, P01, and U01 awards (37\% vs. $17.7 \%, \mathrm{p}<0.01)$. SUS members were two times more likely to be serving in divisional leadership or chair positions $(23.5 \%$ vs. $10.2 \%, \mathrm{p}<0.05)$.

Conclusions: SUS society members are academically a highly productive group. These data support the premise that the SUS is meeting its research mission and identify its members as very academically productive contributors to research and scholarship in American surgery and medicine. 


\section{$\underline{\text { Introduction }}$}

Defining success for an individual academic surgeon may be based on number of publications, number of citations, and external funding, especially from the National Institute of Health (NIH) [1]. These indices are impartial and validated metrics to assess academic productivity and are often considered the best way to evaluate individual academic accomplishment [2]. These metrics also play a vital role in the determination of academic promotion [3] and entry into academic organizations and societies $[4,5]$. Publications and citations are also used to determine journal impact and significance [6] [7].

Journals emphasize their metrics when comparing to other journals [8]. These metrics are readily available for every journal. While not exhaustive, some data do exist on the metrics between different departments within medical schools [9]. The authors of this study have previously demonstrated within academic surgical departments, scholarly productivity is driven by divisions of research, general surgery, and transplant surgery [10].

The Society of University Surgeons (SUS) represents one of the most respected surgical societies with regards to promotion of academic research and scholarship. While academic metrics and other criteria are routinely used to attain membership in academic organizations and societies, there is great variation in how they are used [4, 5, 11-13]. The objective of this study was to evaluate the impact of membership in the SUS on the academic productivity of its constituent members. Furthermore, SUS members were compared with non-members to identify departments and divisions in which the impact of this membership was the greatest. 


\section{Methods and Materials}

$\underline{\text { Selection of Institutions }}$

The top 50-ranked-university based departments of surgery were identified based on current NIH funding available from the Blue Ridge Institute for Medical Research [14]. A Medline search and review of current meetings was performed to identify any additional institutions that had significant academic impact, but were not identified on the NIH funding rank list. This search identified 5 additional hospital-based departments of surgery. All of these were associated with, but separate from, a medical school. These 55 departments of surgery were then ranked based on the NIH funding received by each department.

\section{$\underline{\text { Faculty Demographics and Metrics }}$}

Once the top $55 \mathrm{NIH}$-funded departments of surgery were identified, demographic and academic metrics on each of the faculty members was collected. Using the online website for each of the identified departments of surgery, the following demographic variables for each listed surgeon and research faculty was collected: academic degrees, academic rank, career track (clinical versus research), specialty, division, and any titles held such as division chief, or chairman/chairwoman. Elsevier's SCOPUS bibliographical database (http://proxyauth.uits.iu.edu/auth/ulib/p.?url=http://scopus.com), the NIH Research Portfolio Online Reporting Tools (RePORT)(http://report.nih.gov), and Grantome (http:grantome.com) databases were used to obtain additional data including number of publications, number of citations, H-index, and the type and number of NIH grants awarded for each of these faculty.

\section{$\underline{\text { SCOPUS }}$}

Using the SCOPUS database, the individual scholarly metrics for each faculty member including total publications, total career citations, number of citations in the past 3 years, and $\mathrm{H}$-index were determined. SCOPUS was accessed online at http://scopus.com.proxy.medlib.iupui.edu. Data collection occurred from 9/012014 through 1/31/2015.

\section{$\underline{\text { NIH Funding }}$}

Data on research funding from the NIH was also collected on each faculty member identified in the database. The NIH RePORT online data repository of funding was searched and crosschecked with the Grantome online database. Data points collected included the type of NIH funding in current (2014) United States (US) dollar amounts, the total funding amount in US dollars, the type of NIH grant (RO1, U01, F32, etc.), the funding agency (National Cancer Institute, NAI, NIGMS, etc.), and the number of NIH grants. These data were then used to create a binned variable to categorize the NIH funding. The bins that were created included the following categories: (1) no current or no history of NIH funding, (2) NIH R01/U01/P01 funding, and (3) smaller NIH grants (F32, R03, T32, R32, etc.). 


\section{Determining SUS Membership}

The SUS membership registry was then queried and cross-referenced with the database of faculty members from the top 55-NIH funded departments of surgery. All faculty members with SUS membership were identified as such.

\section{Database and Statistical Analysis}

Data from each of the sources was collated into a master database. The variables in the database were categorized as either continuous or categorical. Continuous variables included total number of publications, total career citations, 3-year citations, H-indices, and rank of the department of surgery by total NIH funding. Institutions were then grouped into quintiles based on this funding. The rank bins were numbered 1-10, 11-20, 21-30, 31-40, 41-50. The 5 hospital-based departments were excluded from the rank bins. Categorical variables included SUS membership, academic rank, divisions, credentials, gender, type of NIH funding, status of current NIH funding, and institutional rank group of NIH funding.

Trend analysis by deciles of NIH funding rank and descriptive statistics were performed. Median and standard deviations were calculated for total publications, total- and 3-year citations, and $\mathrm{H}-$ indices. Group comparisons were performed across the different categorical variables. Continuous variables were compared with t-test of the means for two groups and ANOVA for comparison of multiple groups. Differences between categorical variables were tested using $\mathrm{X}^{2}$ and Mann-Whitney U tests, as appropriate. A p value of $<0.05$ was set to establish statistical significance. All statistical tests were performed using SPSS for Windows, Version 15.0, Chicago, IL, SPSS Inc. All statistical analyses were performed with consultation from a biostatistician (TP). 


\section{$\underline{\text { Results }}$}

$\underline{\text { SUS Members hold higher academic rank and more divisional leadership (Table 1) }}$

After compiling the data, a total of 4,089 surgeons were identified. There were 502 members $(12.5 \%)$ of the SUS compared to 3,587 (87.5\%) non-SUS members. SUS members held the academic rank of Professor 67.7\%, Associate Professor 24.9\%, and Assistant Professor 7.3\% of the time. Non-SUS members held the academic rank of Professor 31.7\%, Associate Professor $27.3 \%$, and Assistant Professor $41 \%$ of the time. SUS members were more likely to hold departmental or divisional leadership positions than non-SUS members, $23.5 \%$ vs. $10.2 \%$ $(\mathrm{p}<0.001)$.

$\underline{\text { SUS Members have more publications and citations regardless of academic rank (Table 1) }}$

The median number of publications and citations for SUS members, regardless of academic rank was 112 and 2460, respectively, while the same medians for non-SUS members were 29 and 467 , respectively (Table 1). SUS members who held the rank of Professor had a median of 141 publications and 3537 citations compared to non-SUS members holding the rank of Professor with 81 and 1856, respectively ( $\mathrm{p}<0.001)$ (Table 1$)$. SUS members holding the rank of Associate Professor also academically outperformed their non-SUS counterparts with a median of 61 publications versus 36 , and 1199 citations versus 591, respectively ( $<<0.001)$ (Table 1 ). Assistant Professors who are SUS members outperformed non-SUS members as well, with a median of 55 publications and 552 citations versus 15 publications and 184 citations $(\mathrm{p}<0.001)($ Table 1$)$.

$\underline{\text { SUS Members obtain more NIH funding than non-SUS members (Table 1) }}$

When reviewing NIH funding, $18.1 \%$ of SUS members currently have such funding through R01, P01, or U01 grants compared to only 7\% of non-SUS members $(\mathrm{p}<0.001)$. Looking specifically at R01 grants, $31.3 \%$ of SUS members currently have an active R01 grant while only $6.6 \%$ of non-SUS members currently have an active R01 grant ( $<0.001$ ). Finally, only $50.6 \%$ of SUS members have no current or never have had NIH funding compared with $85.6 \%$ of nonSUS members $(\mathrm{p}<0.001)$.

$\underline{\text { SUS members outperformed non-SUS members within their respective divisions (Table 2) }}$

SUS membership is, for the most part, equally distributed between divisions of a Department of Surgery. General Surgery had the highest percent of SUS members with $15.9 \%$, followed by Transplant at $15.1 \%$, Vascular at $14.9 \%$, Pediatric at $13.7 \%$, Cardiothoracic at $11.2 \%$, Research at $4.1 \%$, and Plastics at $3.3 \%$ (Table 2). Within each division, SUS members outperformed nonSUS members with statistically significant differences in the number of publications and citations (Table 2). Further breakdown of the divisions of General Surgery into Acute Care Surgery, General and Minimally Invasive Surgery, Surgical Oncology, and Trauma and Critical Care, along with dividing Cardiothoracic into Cardiac Surgery and Thoracic Surgery, showed a 
statistically significant difference between the SUS members and their non-SUS counterparts in regards to publications and citations, also (Table 2).

Membership in the SUS is strongly predictive of higher academic productivity (Table 3)

Multivariate analysis of predictors of academic success showed that membership in the SUS was an independent predictor and carried an increase in publications of $73.3(\mathrm{p}<0.001)$ and citations of $333.26(p<0.001)$ (Table 3). Other independent predictors of academic success identified were having NIH funding, with R01, P01, or U01 grants increasing publications by 70.56 $(\mathrm{p}<0.001)$ (Table 3$)$ and citations by $314.16(\mathrm{p}=0.019)$ (Table 3 ) when compared to individuals without NIH funding. Surgeons with any NIH funding had an increase in publications of 57.68 $(p<0.001)$ (Table 3$)$ and citations of $420.5(p<0.001)$ (Table 3$)$ versus those without funding. Faculty members in high performing academic divisions, which included surgical oncology, transplant surgery, and cardiothoracic surgery, had an increase in number of publications of 9.47 $(p=0.039)$ (Table 3); however, there was no statistical increase in number of citations. Surgical faculty having a Ph.D. (M.D., Ph.D. or Ph.D.) or being in a top $10 \mathrm{NIH}$ funded department of surgery was not independently predictive of any increase in academic productivity based on number of publications and citations. 


\section{$\underline{\text { Discussion }}$}

Number of publications and the impact of the scholarly work are two important measures of faculty accomplishment in academic surgery [15-17]. These metrics are used for criteria in determining appointment and promotion in academic surgical departments and in attaining membership in surgical societies [4, 5, 18-20]. Faculty within departments of surgery, along with other clinical departments, are required to meet a variety of expectations which include providing excellent patient care, the teaching of residents and other trainees, and conducting research. This manuscript sought to evaluate the impact of membership in the Society of University Surgeons on the academic productivity of surgeons.

The data show that SUS members are not only highly academically productive, but they are significantly more productive than non-SUS members. Comparing all SUS members versus nonSUS members it was noted that SUS members have a significantly higher median number of publications and citations. Even when controlled for other variables such as academic rank, additional degrees such as a Ph.D. and NIH funding, SUS members still outperform non-SUS members academically.

It is well established that the number of publications and citations correlate with academic rank and this has been shown in multiple specialties including General Surgery, Neurosurgery, Otolaryngology, Urology, and Anesthesia [10, 21-24]. Here it is demonstrated that membership in an academic surgical society, the SUS, is also correlated with an increased number of publications and citations. To our knowledge this is the first time an individual academic society has been demonstrated to be associated with increased academic productivity and scholarly activity.

In addition to number of publications and citations, NIH funding is used as a measure of academic productivity. Obtaining NIH funding, specifically a R01 grant, is considered by many to be the gold standard for funding support. The R01 grant is highly competitive with an initial success rate of $15.4 \%$ [25] and receiving one is considered a major milestone in a surgeon's career. The data show that SUS members are more likely to have a R01 grant than non-SUS members, $18.1 \%$ versus $7.0 \%$. In addition, the data show that SUS members are more likely have had some type of NIH funding at some point in their career than non-SUS members. As with publications and citations, this is the first time it has been demonstrated that membership in an academic society has been correlated with increased funding.

Reasons for joining surgical societies are numerous and include networking, opportunities to attend and present at meetings and conferences, leadership opportunities, opportunities to shape the future of surgery, and to improve clinical practice [26]. Here the data have demonstrated that improved academic productivity and scholarly activity is another potential benefit to joining surgical societies and that this is especially true in regards to the SUS. 
One could argue that the increased funding is the reason for increased academic productivity. When the SUS members with R01 grants were compared to non-SUS members with R01 grants however, it was observed that SUS members again outperformed non-SUS members with a median number of publication and citations being 148 and 3988 (SUS) versus 103 and 3302 (non-SUS), respectively.

This higher academic productivity is likely a major factor in SUS members being more likely to attain higher academic ranks and positions of departmental or divisional leadership than nonSUS members. As previously noted, $97.2 \%$ of SUS members hold the rank of Associate or full Professor, while only $59 \%$ of non-SUS members hold the same ranks. In addition, SUS members are far more likely to be full Professors than non-SUS members, $67.7 \%$ versus $31.7 \%$, respectively. Finally, $23.5 \%$ of SUS members are in positions of departmental or divisional leadership compared to $10.2 \%$ of non-SUS members. Given that academic productivity based on publications and citations is one of the criteria considered for promotion [18-20], it should not be a surprise that SUS members tend to hold higher academic appointments.

It has been shown that academic productivity within a department of surgery is highly driven by the divisions of General Surgery, Transplant Surgery, and Research [10]. When controlled for division, SUS members are, for the most part, equally represented among the different divisions, with the exceptions being Plastic Surgery and Science and Research. Within each division, it held true that SUS members were more productive with higher median publications and citations.

Using multivariate analysis to identify factors predictive of increased number of publications and citations, SUS membership and NIH funding were independent predictors of an increased number of publications and citations. NIH funding has previously been shown to correlate with increased publications and citations [27]. To our knowledge this is the first time that membership in a surgical society has also been shown to be an independent predictor of increased number of publications and citations. Also, it was interesting to note that SUS membership was predictive of a larger increase in publications, 73.3 versus 70.56 , and citations, 333.26 versus 314.16 , than NIH funding with a R01, P01, or U01 grant.

Taking all of the data into consideration it is clear that membership in the SUS is associated with increased academic productivity and scholarly activity. Additional studies need to be performed analyzing the effects of membership in other surgical societies on academic productivity. From these additional analyses it could be determined if these findings hold true among all surgical societies, a few surgical societies, or only the SUS. Surgeons would then be able to use these analyses to determine which surgical societies would be the best to join in order to achieve their individual career goals.

There are limitations to this study, particularly in regards to the available data sources. Departmental websites were used to obtain the names of faculty at each institution and, 
depending on the date of the last update, may not be completely accurate. Also, difficult to navigate websites or common names may have resulted in missed faculty or incorrect attributions. In order to minimize errors in data collection, a stringent data management system and two-person verification were used.

Two sources for NIH funding were queried; however, due to the 6-month data collection period, some of the funding history may have changed. The publication and citation data may have changed, as well. The data for this study were collected from January, 2014, and July, 2014. In order to minimize discrepancies in faculty members' publications, citations, NIH funding, academic rank, departmental and divisional leadership positions, and SUS membership status, all data for an individual faculty member was collected at the same time. It is anticipated that this relatively short time period for collection resulted in minimal discrepancies between all data points. The authors acknowledge that these data points are fluid and subject to change and, thus, these results are only reflective of the time of collection. Given the strong statistical differences however, it is anticipated that similar studies will show the same overall results namely, that SUS members have more publications and citations, more often hold higher academic rank and positions of departmental and divisional leadership, are more likely to have NIH funding when compared to non-SUS members, and that SUS membership is an independent predictor of an increased number of publications and citations.

The authors acknowledge that number of publications and citations and NIH funding are not the only measures of academic success. Clinical productivity is likely an important confounder in this analysis, and we are unable to account for clinical productivity of the faculty members in this dataset.

\section{Conclusion}

This study examined the academic productivity of SUS members versus non-SUS members at the top 55-NIH funded departments of surgery. The data show that SUS members out perform non-SUS member peers in academic productivity. This supports the premise that the SUS is achieving its research mission. The role of SUS members as leaders in American surgery is confirmed as they are more likely to hold and achieve higher academic rank and to serve in leadership roles or chair positions. 


\section{Bibliography}

1. Petersen, A.M., F. Wang, and H.E. Stanley, Methods for measuring the citations and productivity of scientists across time and discipline. Physical Review E. Statistical, nonlinear, and soft matter physics, 2010.81.

2. Carpenter, C.R., D.C. Cone, and C.C. Sarli, Using Publication Metrics to Highlight Academic Productivity and Research Impact. Academic Emergency Medicine, 2014. 21(10): p. 1160-1172.

3. Lieberman, E., et al., Criteria for Appointment and Promotion. Harvard Medical School and Harvard School of Dental Medicine. 2008.

4. Surgeons, S.o.U. SUS Membership Guidelines. 2012 August 21, 2015]; Available from: http://www.susweb.org/membership-criteria.

5. Association, A.S. Membership in the American Surgical Association. 2015 [cited 2015 October 20]; Available from: http://americansurgical.org/files/2014/Criteria-and-ProcessASA.pdf.

6. Housri, N., et al., SUS/AAS abstracts: what is the scientific impact? Surgery, 2008. 144(2): p. 322-331.

7. Hunt, G.E., M. Cleary, and G. Walter, Psychiatry and the Hirsch h-index: The Relationship Between Journal Impact Factors and Accrued Citations. Harvard Review of Psychiatry, 2015. 18(4): p. 207-219.

8. Saha, S., S. Saint, and D.A. Christakis, Impact factor: a valid measure of journal quality? Journal of the Medical Library Association, 2003. 91(1): p. 42-46.

9. Ozomaro, U., et al., How Important Is the Contribution of Surgical Specialties to a Medical School's NIH Funding? Journal of Surgical Research, 2007. 141(1): p. 16-21.

10. Valsangkar, N.P., et al., Determing the Drivers of Academic Success in Surgery: An Analysis of 3,850 Faculty. Public Library of Science ONE, 2015.

11. Oncology, S.o.S. Membership Benefits and Applications. 2014 [cited 2015 October 20]; Available from: http://www.surgonc.org/about-sso/join-now.

12. Surgeons, A.C.o. Statement on Principles. 2014 March 2014 [cited 2015 October 20]; Available from: https://http://www.facs.org/about-acs/statements/stonprin.

13. Association, T.S.S. Application for Fellowship. [cited 2015 October 20]; Available from: http://www.southernsurg.org/downloads/SSAApplicationFellowshipForm.pdf.

14. Robert Roskoski, J. Blue Ridge Institute for Medical Research. 2014 [cited 2015 August 22]; Available from: http://www.brimr.org.

15. Pagel, P.S. and J.A. Hudetz, H-index is a sensitive indicator of academic activity in highly productive anaesthesiologists: results of a bibliometric analysis. Acta

Anaesthesioligica Scandinavica, 2011. 55(9): p. 1085-1089.

16. Atasoylu, A.A., et al., Promotion Criteria for Clinician-educators. Journal of General Internal Medicine, 2003. 18(9): p. 711-616.

17. Beasley, B.W., et al., Promotion Criteria for Clinician-Educators in the United States and Canada-A Survey of Promotion Committee Chairpersons. Journal of the American Medical Association, 1997. 278(9): p. 723-728.

18. Medicine, H.M.S.a.H.S.o.D. Criteria for Appointment and Promotion. 2008 [cited 2015 October 20]; Available from: http://facultypromotions.hms.harvard.edu/promotions.pdf.

19. Medicine, B.U.S.o. Appointments and Promotions. 2015 [cited 2015 October 20]; Available from: http://www.bumc.bu.edu/facdev-medicine/key-documents/appointmentsand-promotions/. 
20. Medicine, I.U.S.o. Recruitment \& Appointment Resources. 2015 [cited 2015 October 20]; Available from: http://faculty.medicine.iu.edu/recruitment/recruitment-resources/.

21. Spearman, C.M., et al., Survey of the $h$ index for all of academic neurosurgery: another power-law phenomenon. Journal of Neurosurgery, 2010. 113(5): p. 929-933.

22. Svider, P.F., et al., The use of the h-index in academic otolaryngology. Laryngoscope, 2013. 123(1): p. 103-106.

23. Colaco, M., et al., Is There a Relationship between National Institutes of Health Funding and Research Impact on Academic Urology? The Journal of Urology, 2013. 190(3): p. 999-1003.

24. Pagel, P.S. and J.A. Hudetz, An analysis of scholarly productivity in United States academic anaesthesiologists by citation bibliometrics. Anaesthesia, 2011. 66(10): p. 873878.

25. RePORT, N. Research Project Success Rates by Type and Activity for 2014. 2014 [cited 2015 October 20]; Available from:

http://report.nih.gov/success_rates/Success ByActivity.cfm.

26. Kao, L.S., How to Get Involved and Contributed Through Participation in Surgical Societies. 2013, Association for Academic Surgery.

27. Svider, P.F., et al., Is NIH funding predictive of greater research productivity and impact among academic otolaryngologists? The Laryngoscope, 2013. 123(1): p. 118-122. 
Table 1 Overall comparison of academic output between AAS members and AAS non-members

\begin{tabular}{llll}
\hline Parameter & \multicolumn{2}{l}{ SUS membership status } \\
& SUS member & SUS non-member & P value \\
\hline Overall & & & \\
\hline Academic Rank & & & \\
Publications & $112+150$ & $29+74$ & $<0.001$ \\
Citations & $2460+4849$ & $467+2548$ & $<0.001$ \\
3-year citations & $597+995$ & $148+900$ & $<0.001$ \\
H- index & $25+15$ & $10+11$ & $<0.001$ \\
\hline
\end{tabular}


Table 2 Comparisons of the academic characteristics between SUS members and non-members

\begin{tabular}{|c|c|c|c|c|c|}
\hline \multirow[t]{2}{*}{ Parameter } & \multicolumn{2}{|c|}{ SUS member } & \multicolumn{3}{|c|}{ SUS non-member } \\
\hline & $\mathrm{N}, \%$ & $\begin{array}{l}\text { Publications, Citations } \pm \\
\text { SD }\end{array}$ & $\mathrm{N}, \%$ & Publications, Citations \pm SD & $\mathbf{P}$ \\
\hline Overall & 502,10 & & $\begin{array}{l}3587 \\
100 \%\end{array}$ & & \\
\hline \multicolumn{6}{|l|}{ Academic Rank } \\
\hline Assistant professor & $7.3 \%$ & $55+75,552+2146$ & $41 \%$ & $15+39,184+945$ & $<0.001$ \\
\hline Associate Professor & $24.9 \%$ & $61+49,1199+2959$ & $27.3 \%$ & $36+39,591+1406$ & $<0.001$ \\
\hline Professor & $67.7 \%$ & $141+169,3537+5371$ & $31.7 \%$ & $81+99,1856+3752$ & $<0.001$ \\
\hline \multicolumn{6}{|l|}{ Divisional Leadership } \\
\hline Yes & $23.5 \%$ & $137+151,3509+5154$ & $10.2 \%$ & $62+85,1300+3108$ & $<0.001$ \\
\hline No & $76.5 \%$ & $107+150,2221+4782$ & $89.8 \%$ & $27+72,444+2518$ & $<0.001$ \\
\hline \multicolumn{6}{|l|}{ Degree } \\
\hline MD & 90.1 & $107+148,2267+4679$ & $89.3 \%$ & $27+69,408+2453$ & $<0.001$ \\
\hline MD-PhD & 8.8 & $128+125,3016+4840$ & $4.2 \%$ & $40+118,988+3707$ & $<0.001$ \\
\hline $\mathrm{PhD}$ & 1.1 & $124+107,3640+5594$ & $6.6 \%$ & $41+91,1276+2370$ & $<0.001$ \\
\hline \multicolumn{6}{|l|}{ NIH funding } \\
\hline R01/P01/U01 grant & $18.1 \%$ & $148+221,3988+6665$ & $7.0 \%$ & $103+130,3302+4666$ & $<0.001$ \\
\hline \multirow{2}{*}{$\begin{array}{l}\text { Non-R01 grant } \\
\text { No current/former NIH } \\
\text { funding }\end{array}$} & $31.3 \%$ & $95+81,1805+3732$ & $6.6 \%$ & $52+69,1113+2408$ & $<0.001$ \\
\hline & $50.6 \%$ & $93+94,1830+3301$ & $86.5 \%$ & $24+61,366+2017$ & $<0.001$ \\
\hline
\end{tabular}


Table 3 Analysis of the distribution of SUS members in each division and their academic productivity

\begin{tabular}{llllll}
\hline Division & SUS member & Non-member & P \\
\hline $\begin{array}{l}\text { Percentage within } \\
\text { division that are SUS } \\
\text { members }\end{array}$ & Percent & $\begin{array}{l}\text { Publications } \pm \text { SD, } \\
\text { Citations } \pm \text { SD }\end{array}$ & Percent & $\begin{array}{l}\text { Publications } \pm \text { SD, } \\
\text { Citations } \pm \text { SD }\end{array}$ \\
\hline $\begin{array}{l}\text { Cardiothoracic surgery } \\
\text { Cardiac surgery }\end{array}$ & $11.2 \%$ & $154 \pm 111,3596 \pm 4731$ & $88.8 \%$ & $37 \pm 76,726 \pm 2522$ & $<0.001$ \\
$\quad 10.6 \%$ & $168 \pm 98,4407 \pm 5885$ & $89.4 \%$ & $43 \pm 86,589 \pm 2588$ & $<0.001$ \\
$\quad$ Thoracic surgery & $11.5 \%$ & $137 \pm 119,2909 \pm 3955$ & $88.5 \%$ & $36 \pm 69,793 \pm 2485$ & $<0.001$ \\
General Surgery & $15.9 \%$ & $106 \pm 100,2291 \pm 3706$ & $84.1 \%$ & $24 \pm 70,405 \pm 2831$ & $<0.001$ \\
$\quad$ Acute Care Surgery & $10.7 \%$ & $110 \pm 50,3523 \pm 1259$ & $89.3 \%$ & $13 \pm 38,209 \pm 1151$ & $<0.001$ \\
$\quad$ General and & $14.6 \%$ & $103 \pm 101,2196 \pm 3564$ & $85.4 \%$ & $24 \pm 75,423 \pm 2746$ & $<0.001$ \\
$\quad \begin{array}{l}\text { Minimally Invasive } \\
\quad \text { Surgical Oncology }\end{array}$ & $22.6 \%$ & $116 \pm 102,2834 \pm 4252$ & $77.4 \%$ & $32 \pm 75,524 \pm 3614$ & $<0.001$ \\
$\quad$ Trauma/Critical Care & $12.5 \%$ & $116 \pm 81,1544 \pm 5111$ & $87.5 \%$ & $16 \pm 51,236 \pm 1835$ & $<0.001$ \\
Pediatric Surgery & $13.7 \%$ & $88 \pm 100,1556 \pm 2805$ & $86.3 \%$ & $28 \pm 75,467 \pm 2132$ & $<0.001$ \\
Plastic Surgery & $3.3 \%$ & $196 \pm 175,3725 \pm 2524$ & $96.7 \%$ & $23 \pm 45,324 \pm 1182$ & $<0.001$ \\
Science/Research & $4.1 \%$ & $189 \pm 112,4470 \pm 5912$ & $95.9 \%$ & $54 \pm 55,1401 \pm 1621$ & $<0.001$ \\
Transplant & $15.1 \%$ & $130 \pm 287,3259 \pm 8518$ & $84.9 \%$ & $47 \pm 110,863 \pm 3251$ & $<0.001$ \\
Vascular surgery & $14.9 \%$ & $91 \pm 70,2718 \pm 2813$ & $85.1 \%$ & $29 \pm 77,441 \pm 1828$ & $<0.001$ \\
\hline
\end{tabular}


Table 3 Comparisons of the academic characteristics between AAS members and AAS non-members

\begin{tabular}{|c|c|c|c|}
\hline \multirow[t]{2}{*}{ Parameter } & \multicolumn{2}{|l|}{ SUS member } & SUS non-member \\
\hline & $\mathrm{N}, \%$ & Publications, Citations \pm SD & $\mathrm{N}, \% \quad$ Publications, Citations \pm SD \\
\hline \multicolumn{4}{|l|}{ Overall } \\
\hline \multicolumn{4}{|l|}{ NIH funding } \\
\hline \multicolumn{4}{|c|}{ No NIH funding } \\
\hline \multicolumn{4}{|c|}{ NIH R01/P01/U01 Awards } \\
\hline \multicolumn{4}{|c|}{$\begin{array}{l}\text { NIH non-R01 awards (R21, } \\
\text { K08...) }\end{array}$} \\
\hline \multicolumn{4}{|c|}{$\begin{array}{l}\text { Funding Agencies for } \\
\text { funded faculty }\end{array}$} \\
\hline \multicolumn{4}{|c|}{ R01 } \\
\hline \multicolumn{4}{|l|}{ Non-R01 } \\
\hline \multicolumn{4}{|c|}{ Other society memberships } \\
\hline \multicolumn{4}{|c|}{ AAS } \\
\hline \multicolumn{4}{|l|}{ sso } \\
\hline \multicolumn{4}{|l|}{$\mathrm{PhD}$} \\
\hline \multicolumn{4}{|c|}{ K08 awards } \\
\hline \multicolumn{4}{|c|}{ R01/P01/U01 grant } \\
\hline \multicolumn{4}{|l|}{ Non-R01 grant } \\
\hline \multicolumn{4}{|c|}{ No current/former NIH funding } \\
\hline \multicolumn{4}{|c|}{ Institutional Characteristics } \\
\hline \multicolumn{4}{|c|}{$\mathrm{NCl}$ membership } \\
\hline \multicolumn{4}{|l|}{ SSO memberships } \\
\hline \multicolumn{4}{|c|}{ Fellowships offered } \\
\hline \multicolumn{4}{|c|}{ Acute Care Surgery } \\
\hline \multicolumn{4}{|c|}{$\begin{array}{l}\text { General and } \\
\text { Minimally Invasive }\end{array}$} \\
\hline \multicolumn{4}{|c|}{ Surgical Oncology } \\
\hline \multicolumn{4}{|c|}{ Trauma/Critical Care } \\
\hline \multicolumn{4}{|c|}{ Integrated training programs } \\
\hline \multicolumn{4}{|c|}{ Vascular } \\
\hline \multicolumn{4}{|l|}{ Cardiothoracic } \\
\hline Pediatric surgery & & & \\
\hline
\end{tabular}


Table 4 Multivariate analysis of the predictors of academic success as defined by publications and citations

\begin{tabular}{|c|c|c|}
\hline Predictive Factors & $\begin{array}{l}\text { Unstandardized Coefficients } \beta \\
\text { (number of publications/citations } \\
\text { added per dependant variable unit) }\end{array}$ & $P$ value \\
\hline \multicolumn{3}{|l|}{ Publications } \\
\hline Membership of the SUS & 73.3 & $<0.001$ \\
\hline \multicolumn{3}{|l|}{ NIH Funding } \\
\hline NIH R01/P01/U01 funding vs. No funding & 70.56 & $<0.001$ \\
\hline Any NIH funding vs. No funding & 57.68 & $<0.001$ \\
\hline $\begin{array}{l}\text { Faculty member in a higher performing division (surgical } \\
\text { oncology, transplant, cardiothoracic surgery) }\end{array}$ & 9.47 & 0.039 \\
\hline Faculty member has a PhD (MD PhD or PhD) & - & N.S \\
\hline Faculty member at top-10 $\mathrm{NIH}$ funded department of surgery & - & N.S. \\
\hline \multicolumn{3}{|l|}{ Citations } \\
\hline Publications & 30.45 & $<0.001$ \\
\hline Membership of the SUS & -333.26 & $<0.001$ \\
\hline \multicolumn{3}{|l|}{ NIH Funding } \\
\hline NIH R01/P01/U01 funding vs. No funding & 314.16 & 0.019 \\
\hline Any NIH funding vs. No funding & 420.59 & $<0.001$ \\
\hline $\begin{array}{l}\text { Faculty member in a higher performing division (surgical } \\
\text { oncology, transplant, cardiothoracic surgery) }\end{array}$ & - & N.S \\
\hline Faculty member has a PhD (MD PhD or PhD) & - & N.S \\
\hline Faculty member at top-10 NIH funded department of surgery & - & N.S \\
\hline
\end{tabular}


